\title{
A phase III trial of topotecan and whole brain radiation therapy for patients with CNS-metastases due to lung cancer
}

\author{
T Neuhaus', Y Ko*,I, RP Muller², GG Grabenbauer ${ }^{3}$, JP Hedde ${ }^{4}$, H Schueller ${ }^{5}$, M Kocher $^{2}$, S Stier $^{6}$ \\ and R Fietkau ${ }^{7}$ \\ 'Johanniter-Krankenhaus, Bonn, Germany; ${ }^{2}$ Klinik für Strahlentherapie, Uniklinikum Köln, Köln, Germany; ${ }^{3}$ Klinik für Strahlentherapie, Uniklinikum \\ Erlangen, Erlangen, Germany; ${ }^{4}$ Städt. Krankenhaus, Köln-Merheim, Germany; ${ }^{5}$ Klinik für Strahlentherapie, Uniklinikum Bonn, Bonn, Germany; \\ ${ }^{6}$ Med. Poliklinik, Uniklinikum Bonn, Bonn, Germany; ${ }^{7}$ Klinik für Strahlentherapie, Uniklinikum Rostock, Rostock, Germany
}

\begin{abstract}
Brain metastases represent an important cause of morbidity in patients with lung cancer and are associated with a mean survival of less than 6 months. Thus, new regimens improving the outcome of these patients are urgently needed. On the basis of promising data raised in a phase I/II trial, we initiated an open, randomised, prospective, multicentric phase III trial, comparing whole brain radiation therapy (WBRT; $20 \times 2 \mathrm{~Gy}$ ) alone with WBRT + topotecan (RCT; $0.4 \mathrm{mg} \mathrm{m}^{-2}$ day $\left.^{-1} \times 20\right)$. A total of 320 patients with CNSmetastases due to SCLC or NSCLC were projected. The primary end point was overall survival, whereas second end points were local response and progression-free survival. However, until the cutoff date of study completion (i.e., a study duration of 34 months), only a total of 96 (RCT:47, WBRT:49) patients had been recruited, and so an analysis was performed at that time point. Although the numbers of grade 3/4 non-haematological toxicities (besides alopecia II 5 (RCTMBRT: 55 out of 60) were evenly distributed, the 25 haematological events occurred mainly in the combined treatment arm (24 out of I). Local response, evaluated 2 weeks after treatment, was assessable in 44 (RCT/WBRT: 23 out of 21 ) patients, showing CR in eight (3 out of 5), PR in 17 ( I I out of 6), SD in I4 (8 out of 6 ) and PD in five (I out of 4) patients (all differences n.s.). Neither OAS (RCTMBRT: median (days)): 87 out of 95, range 3-752/4-433; HR I.32; 95\% Cl $(0.83 ; 2.10)$ ) nor PFS (median (days)): 7l out of 66, range, 3-399/4-228; $\mathrm{HR} \mathrm{I.28,} \mathrm{95 \%} \mathrm{Cl}$ $(0.73 ; 2.43)$ differed significantly. On the basis of these results and the slow recruitment, a continuation of the study did not seem reasonable. The available data show no significant advantage for concurrent radiochemotherapy for patients with lung cancer; however, the recruited number of patients is too low to exhibit a small advantage of combined treatment.
\end{abstract}

British Journal of Cancer (2009) I 00, 29|-297. doi: 10.1038/sj.bjc.6604835 www.bjcancer.com

Published online 6 January 2009

(c) 2009 Cancer Research UK

Keywords: brain metastases; lung cancer; radiochemotherapy; topotecan

Brain metastases represent an important cause of morbidity in patients with solid tumours. Most often, they were found in cancers of the lung with incidences in autoptic series of $54 \%$ in NSCLC and $80 \%$ in SCLC (Riva et al, 2001), and these tumour types account for more than one half of all brain metastases (Zimm et al, 1981).

Besides the local neurological complications, the occurrence of brain metastases is also a sign of systemic failure of tumour control, going ahead with a median survival time in untreated patients of about 1 month (Sundstrom et al, 1998). Thus, the treatment of brain metastases should focus on both, the control of neurological symptoms as well as a prolonged survival rate.

Although in patients with a limited number of CNS-metastases, surgery or stereotactic radiosurgery represents important therapeutic approaches (Patchell et al, 1990; Andrews et al, 2004; Jawahar et al, 2004), in those patients with multiple CNSmetastases, Whole Brain Radiotherapy (WBRT) is still the treatment of choice. A reduction of neurological complications is

\footnotetext{
* Correspondence: Dr Y Ko, Johanniter-krankenhaus, Johanniterstrasse 3-5, Bonn, Germany; E-mail: y.ko@ek-bonn.de

Revised 25 November 2008; accepted 25 November 2008; published online 6 January 2009
}

mostly achieved however, it results only in an overall survival benefit of approximately 4 months (Lagerwaard et al, 1999; Postmus, 1995; Saito et al, 2006), and a control of brain metastases will be found in only $50 \%$ of the patients (Lassman and DeAngelis, 2003).

As an alternative, the efficacy of chemotherapy in the treatment of brain metastases has been investigated. However, the response rates found in the treatment of brain metastases in mainly nonrandomised studies were about $20-40 \%$ with a median survival time varying from 3 to 10 months and have thus been disappointing (Nieder et al, 2006).

Therefore, an improvement of these results is urgently needed. One approach was the addition of radiosensitisers to WBRT. However, the few studies on this subject published to date failed to show any significant effect on overall survival or on local response rate (Tsao et al, 2006).

For multimodal treatment strategies, including combination of chemotherapy (e.g., temozolomide, paclitaxel, nimustine, tegafur) with WBRT, sufficient data are rare, too. Although most of the studies pointed out an improvement in local control compared with WBRT, the median survival times did not differ (Postmus et al, 2000; Robinet et al, 2001; Ushio et al, 1991 Mornex et al, 2003). 
A promising candidate for a combined radiochemotherapy seems to be topotecan, a topoisomerase I inhibitor with a well established activity in the systemic treatment of SCLC (von Pawel et al, 1999) and NSCLC (Stewart, 2004), a high brain capillary permeability (Sung et al, 1994; Baker et al, 1996) and radiosensitising effects (Kim et al, 1992; Lamond et al, 1996). For topotecan in a monotherapeutic setting, response rates of $33-63 \%$ in patients with brain metastases due to SCLC were found (Ardizzoni et al, 1997; Schutte et al, 1999; Korfel et al, 2002; summarised in Wong and Berkenblit, 2004).

As a consequence, three phase I/II-studies were initiated to evaluate the feasibility of topotecan-based combined radiochemotherapy in patients with brain metastases (Gruschow et al, 2002; Kocher et al, 2005; Hedde et al, 2007). In the setting of the doseescalating phase I studies, Gruschow et al (2002) and Hedde et al (2007) found tolerable toxicities in those patients receiving $0.4 \mathrm{mg} \mathrm{m}^{-2}$ day $^{-1}$ topotecan, either as a bolus or continuous infusion, concurrent with the WBRT (fraction size of $2 \mathrm{~Gy} \mathrm{day}^{-1}$ for a total of $40 \mathrm{~Gy}$ ). Kocher et al (2005) used a regimen with local target dosage of $36 \mathrm{~Gy}$ in 3-Gy-fractions and topotecan administered $12 \times 0.5 \mathrm{mg} \mathrm{m}^{-2}$ day $^{-1}$.

In the study published by Hedde et al (2007) 19\% of their 68 patients developed grade 3/4 haematological and 21\% developed grade 3/4 non-haematological events. Of their 47 patients, in whom a local response was assessable, seven presented with complete and 27 with partial responses (i.e. an overall response rate of $72 \%$ ). The median survival of all patients reached 17 weeks and amounted to 33 weeks in responders.

Gruschow et al (2002) included 20 patients and found a median survival of 5 months. In 13 patients, the remission status could be evaluated; four complete and two partial responders were detected, resulting in an overall response rate of $46 \%$.

Of the 47 patients who took part in the study of Kocher et al (2005), response evaluation was possible in 26 patients. In them, an overall response rate of $58 \%$ was described ( 5 out of 26 complete response (CR) and 10 out of 26 partial response (PR)). Grade 3/4 haematological toxicities were found in $25 \%$ of all patients.

On the basis of these promising results, we initiated a phase III study comparing the efficacy of a combined radiochemotherapy with topotecan and WBRT vs WBRT alone in patients with brain metastases from lung cancer.

\section{PATIENTS AND METHODS}

\section{Patient eligibility}

Patients with histologically proven lung cancer and intracerebral metastases have been entered in this open-label, prospective, multicentric, randomised phase III study. Initially only patients with recurrence of lung cancer after first line therapy could be included in the study. However, due to a slow recruitment, after 1 year an amendment allowing the inclusion of primary diagnosed patients was added. Patients were enrolled with ages between $18-$ 75 years, and at least one measurable lesion in the brain was confirmed by computed tomography (CT) or magnetic resonance imaging. Sufficient bone marrow reserve was defined as neutrophil counts $\geqslant 1500 \mu \mathrm{l}^{-1}$, leukocyte counts $\geqslant 3500 \mu \mathrm{l}^{-1}$, platelet counts $\geqslant 100000 \mu \mathrm{l}^{-1}$ and haemoglobin $\geqslant 9 \mathrm{~g} \mathrm{dl}^{-1}$. Adequate renal function was defined by serum creatinine concentration $\leqslant 1.5 \mathrm{mg} \%$ or creatinine clearance $>60 \mathrm{ml} \mathrm{min}^{-1}$. Patients had to have a performance status of $0-2$ according to ECOG criteria.

Exclusion criteria were prior to cerebral radiotherapy and/or surgery of cerebral metastases (except stereotactic biopsy), missing histologically proven nature of cancer, solitary intracerebral metastases suitable for neurosurgery, meningeosis carcinomatosa, active uncontrolled infection, concomitant or previous malignancies, except basal or squamous cell carcinoma or carcinoma in situ of the cervix and history of therapy with and/or known allergy to topoisomerase I inhibitors, pregnant or breast-feeding women. All patients were informed of the investigational nature of the study and had to provide written informed consent. The study was approved by local ethics committees of all participating centres.

Randomisation was performed by considering the parameters SCLC, NSCLC, extracerebral metastases and a number of brain metastases.

\section{Treatment protocol}

Arm A (radiochemotherapy): Topotecan was administered as a $30 \mathrm{~min}$ infusion with $0.4 \mathrm{mg} \mathrm{m}^{-2}$ day $^{-1}$ for 5 days over 4 weeks within $2 \mathrm{~h}$ before radiation therapy. Whole Brain Radiation (WBR) was applied with a fraction size of $2 \mathrm{Gyday}^{-1}$ to a total of $40 \mathrm{~Gy}$. Arm B (Radiotherapy): WBR was applied with a fraction size of $2 \mathrm{~Gy} \mathrm{day}^{-1}$ to a total of $40 \mathrm{~Gy}$.

Continuation therapy: subsequently, patients with extracerebral cancer lesions from both arms had the option to receive three additional cycles of topotecan chemotherapy $\left(1.25 \mathrm{mg} \mathrm{m}^{-2}\right.$ day $^{-1}$, $\mathrm{d} 1-5, \mathrm{q} 21 \mathrm{~d})$, starting on day 15 after the end of WBRT. In case a patient had not received any kind of chemo- or radiochemotherapy before entering the study, the institutionally preferred chemotherapeutic regimen was allowed to be used instead Continuation therapy was stopped after three cycles or when tumour progression of the extracerebral metastases occurred.

\section{Dose delays and modifications}

In the case of severe neutropenia (neutrophil counts $\leqslant 1000 \mu \mathrm{l}^{-1}$ ) or thrombocytopenia (platelet counts $\leqslant 50000 \mu \mathrm{l}^{-1}$ ), topotecan therapy was stopped until recovery of neutrophil counts to $\geqslant 15000 \mu \mathrm{l}^{-1}$ and of platelet counts to $\geqslant 100000 \mu \mathrm{l}^{-1}$. Radiation therapy was continued as planned. Therapeutic use of G-CSF was allowed and left to the decision of the treating physician. Antiemetic and supportive symptom treatment was left to the treating physician as well. For dexamethasone, a dosage of $4 \mathrm{mg}$ two times per day was recommended; the dosage should not exceed $12 \mathrm{mg} \mathrm{day}^{-1}$. During the continuation therapy, a dose reduction of $0.25 \mathrm{mg} \mathrm{m}^{-2}$ day $^{-1}$ topotecan for the next cycle was recommended in the case of thrombocytopenia (platelet counts $\leqslant 50000 \mu \mathrm{l}^{-1}$ ), whereas in the case of neutropenia, G-CSF should be applicated without reduction of the topotecan dosage. Again, therapy was continued after neutrophil counts increased to $\geqslant 15000 \mu \mathrm{l}^{-1}$ and platelet counts to $\geqslant 100000 \mu \mathrm{l}^{-1}$.

\section{Withdrawal from the study}

The treatment was stopped as per the patients' wish, by the decision of the physician, tumour progression, severe side effects according to the NCIC CTCG guidelines or non-compliance of the patient. The whole study was to be stopped in case new therapeutic regimens with superior benefit of either therapy arm were published, if the interim analyses showed that the criteria for stopping the study by using the methods of Pocock (1978) and O'Brien and Fleming (1979) were reached and when the number of patients recruited was clearly below the expected value.

\section{Tumour assessment}

Criteria for efficacy assessment were response rate, progressionfree survival and overall survival. A complete response was defined as a complete disappearance of all evidence of disease in the brain. A partial response was defined as radiological response $>50 \%$ in all brain metastases. Responses in tumour lesions $<50 \%$ or increase in size less than $25 \%$ was defined as stable disease. A progressive disease was defined as either the occurrence of new lesions or an increase in size of more than 25\%. Tumour 
assessment was performed with the method used initially. In addition, death caused by cerebral lesions was assessed if one of the following causes of death were described: Cerebral oedema, neurologic disorders, cramps, dementia and progression of cerebral lesions.

Tumour assessment was also performed for extracerebral lesions. Assessment of brain metastases by imaging was performed on day 15 after the end of radiotherapy/radiochemotherapy; in the case of a complete remission, it was repeated 4 weeks later. The final examination was planned for week 17 for patients with extracerebral tumours, and it included extracranial tumour imaging.

\section{Safety assessment}

Baseline evaluations included medical history, physical examination, radiologic assessment of tumour status by cerebral CT or MR, conventional X-ray or CT of the lung and CT of the upper abdomen, ECOG scale, and laboratory evaluations. Full blood counts and biochemistry were measured weekly. On week 7 (15 days after end of the treatment), the following assessments were performed: physical examination, documentation of side effects, cerebral tumour status, neurologic status, blood counts and blood chemistry. During the continuation therapy full blood counts and biochemistry were measured before each course, and side effects were documented. On week 17, the final examination for all patients included physical examination, extracranial tumour imaging in the case of extracerebral tumours, neurologic status, laboratory evaluations and documentation of palliative treatment. During follow-up visits, the toxicities and palliative treatments were documented every 8 weeks.

\section{Quality of life}

For recording the quality of life we used the EORTC-QLQ C30A questionnaire added by the brain cancer module EORTC-QLQ BN20. The patients should get these questionnaires before treatment, 2 weeks after treatment and at follow-up. However, an analysis was not possible owing to the very low number of returned questionnaires.

\section{Statistical considerations}

The primary end point was overall survival (OAS). Secondary end points were progression-free survival, rates of complete responses of the cerebral lesions, duration of remission, status of the extracerebral tumours after continuation therapy and toxicity.

As mentioned, the primary end point with regard to therapeutic efficacy is the survival time of the patients starting at the randomisation time point. Event is the time of death. The sample size estimate for the study was based on a sequential study design with two samples and an interim analysis. The reference value was the median survival time of 4 months under standard therapy (radiotherapy, Arm B). The estimated minimum clinically relevant therapeutic effect under investigational treatment (radiochemotherapy, Arm A) was an increase in the survival time in the interventional group to 5.5 months. The study protocol justifies the one-sided testing by the fact that a longer survival time in patients under the investigational therapy can be assumed to be highly likely. For the testing of this study design, the estimated number of patients was 320 (i.e., 160 patients per treatment arm with equal distribution). Dropouts were not considered.

An interim analysis was planned after the death of the first 150 patients (event of primary end point); the decision concerning the continuation of the study was based on using the $\alpha$-spending principle with criteria for closing the study described by Pocock (1978) and O'Brien and Fleming, (1979).

Overall survival was defined as the interval from randomisation until death. Progression-free survival was defined as the interval from randomisation until evidence of disease progression or death. Analysis was performed by the Kaplan-Meier estimation. Overall survival and progression-free survival were compared using the log-rank test. Regression analyses were performed by using the Cox proportional hazards model. The analyses of all other secondary end points were evaluated in an explorative or descriptive manner.

\section{RESULTS}

\section{Patient characteristics}

The first patient was included in October 2001. An interim analysis was planned after the death of 150 patients. However, until August 6 , 2004, that is, after a study duration of 34 months, only 95 patients in 11 centres had been recruited, and so the interim analysis was performed at that time point. This analysis did not show any benefit of radiochemotherapy with regard to overall survival and thus, on the basis of the slow recruitment and the result of the interim analysis, a continuation of the study did no longer appear reasonable. The results described here represent the final analysis, in which 96 patients were included.

The demographic data as presented in Table 1 were evenly distributed in the two groups. Most of the patients (64\%) had a good ECOG performance status of $0-1$, and $75 \%$ of the patients had extracerebral metastases. There were 25 patients $(26 \%)$ with more than four CNS-metastases, and $15.6 \%$ of the patients received continuation therapy with topotecan.

Table I Demographic results

\begin{tabular}{|c|c|c|}
\hline & Radiochemotherapy & Radiotherapy \\
\hline No. of patients & 47 & 49 \\
\hline \multicolumn{3}{|l|}{ Age } \\
\hline Median & 58 & 59 \\
\hline Range & $34-75$ & $42-75$ \\
\hline Male/female & $32 / 15$ & $30 / 19$ \\
\hline \multicolumn{3}{|l|}{ Primary site of tumour } \\
\hline NSCLC first line & 7 & 8 \\
\hline NSCLC recurrence & 24 & 24 \\
\hline SCLC first line & 3 & 2 \\
\hline SCLC recurrence & 13 & 15 \\
\hline \multicolumn{3}{|c|}{ ECOG performance status } \\
\hline 0 & 8 & 2 \\
\hline । & 29 & 22 \\
\hline 2 & 7 & 19 \\
\hline 3 & i & 2 \\
\hline Not reported & 2 & 4 \\
\hline \multicolumn{3}{|c|}{ No. of brain metastases $>4$} \\
\hline Yes & 11 & 14 \\
\hline No & 36 & 35 \\
\hline \multicolumn{3}{|l|}{ Extracerebral metastases } \\
\hline Yes & 35 & 37 \\
\hline No & 12 & 12 \\
\hline \multicolumn{3}{|l|}{ Dexamethasone dosing } \\
\hline Yes & 38 & 39 \\
\hline Not & 9 & 8 \\
\hline Not reported & 0 & 2 \\
\hline \multicolumn{3}{|c|}{ Courses of continuation therapy } \\
\hline 1 & I & 2 \\
\hline 2 & I & I \\
\hline 3 & 6 & 4 \\
\hline
\end{tabular}




\section{Safety and tolerability}

Only half of the patients $(51 \%)$ were reported to be treated per protocol, whereas $49 \%$ of the patients were not. The reasons for protocol deviations are mainly early deaths, haematological toxicities, dosage failure, worsening of general condition and tumour progression. In detail, in arm $\mathrm{A}$ the chemotherapy was delayed or reduced in nine patients because of neutropenia, and in six of them G-CSF was given at least once. Although no patient stopped topotecan because of neutropenia, one patient left the study because of prolonged thrombocytopenia.

The main cause of early death (Table 2 ), defined as death within 6 weeks after recruitment, was tumour progression. Early death occurred in $24 \%$ of the patients, and of these $61 \%$ belonged to the arm receiving radiochemotherapy. The main causes of death in general were tumour progression, especially in 18 patients' ( 3 arm A, 15 arm B) progression of cerebral lesions.

The occurrence of non-haematological grade 3/4 toxicities did not differ between both treatment arms (Table 3). In total, besides alopecia found in about $40 \%$ of all patients, 118 non-haematotoxic grade 3/4 adverse events were described. Haematological toxicities occurred - as expected - more often in the radiochemotherapy arm (Table 3). All in all, 25 grade $3 / 4$ haematotoxic adverse events were reported, 24 in the patients receiving the combined approach and one in the patient treated with WBRT alone.

\section{Response}

Response of brain metastases, evaluated about 2 weeks after treatment, was assessable in 44 patients (radiochemotherapy/ radiotherapy: 23 out of 21 ), showing CR in eight ( 3 out of 5), PR in 17 (11 out of 6), stable disease (SD) in 14 (8 out of 6) and progressive disease (PD) in five (1 out of 4 ) patients (Table 4 ). Data concerning the response behaviour of extracerebral metastases after continuation therapy were available in just 10 (radiochemotherapy/radiotherapy: 6 out of 4) patients. Although in the patients receiving radiochemotherapy $2 \mathrm{PR}, 1 \mathrm{SD}$ and $3 \mathrm{PD}$ were found, all four patients in the radiotherapy-arm presented with PD.

Neither overall survival (radiochemotherapy/radiotherapy: median (days): 87 out of 95, range 3-752 out of 4-433; Hazard Ratio 1.32, $95 \%$ CI $0.83-2.1$ ) nor progression-free survival (assessable in 44 patients; median (days): 71 out of 66 , range: $3-399$ out of $4-228$; Hazard Ratio 1.28 , 95\% CI $0.73-2.43$ ) differed significantly between the two groups (using Cox-Mantel test; Figure 1A and B). This was true for SCLC and NSCLC, respectively, and thus the histology of the lung cancer did not seem to influence the response rates.

The co-medication was not analysed in detail, but although serum concentration of topotecan could be diminished in patients treated with inducers of CYP450-enzymes, the investigators negotiated any relevant influence of these inducers on the results of the study.
Table 2 Causes of early death (death within 6 weeks after recruitment)

\begin{tabular}{lcc}
\hline & Radiochemotherapy & Radiotherapy \\
\hline Early death & $14 / 47$ & $9 / 49$ \\
Tumour progression & 7 & 6 \\
Cardiovascular failure & 2 & 0 \\
Pulmonary embolism & 1 & 1 \\
Infection & 2 & 1 \\
Gl-haemorrhage & 2 & 0 \\
Unknown & 0 & 1 \\
\hline
\end{tabular}

Table 4 Response of brain metastases

\begin{tabular}{lcc}
\hline & Radiochemotherapy & Radiotherapy \\
& $\mathbf{4 7}$ & $\mathbf{4 9}$ \\
\hline Complete response (CR) & 3 & 5 \\
Partial response (PR) & 11 & 6 \\
Stable disease (SD) & 8 & 6 \\
Progressive disease (PD) & 1 & 4 \\
Not specified & 2 & 3 \\
Not assessable & 22 & 25 \\
\hline
\end{tabular}

Table 3 Incidence of the main grade 3 and 4 adverse events (by patients)

\begin{tabular}{|c|c|c|c|c|c|c|c|c|}
\hline \multirow[b]{3}{*}{ CTC-Grade } & \multicolumn{4}{|c|}{ Radiochemotherapy } & \multicolumn{4}{|c|}{ Radiotherapy } \\
\hline & \multicolumn{2}{|c|}{ Grade 3} & \multicolumn{2}{|c|}{ Grade 4} & \multicolumn{2}{|c|}{ Grade 3} & \multicolumn{2}{|c|}{ Grade 4} \\
\hline & $\begin{array}{c}\text { No.of } \\
\text { patients }\end{array}$ & $\begin{array}{l}\text { Percentage } \\
\text { of patients }\end{array}$ & $\begin{array}{c}\text { No.of } \\
\text { patients }\end{array}$ & $\begin{array}{l}\text { Percentage } \\
\text { of patients }\end{array}$ & $\begin{array}{c}\text { No.of } \\
\text { patients }\end{array}$ & $\begin{array}{l}\text { Percentage } \\
\text { of patients }\end{array}$ & $\begin{array}{c}\text { No.of } \\
\text { patients }\end{array}$ & $\begin{array}{l}\text { Percentage } \\
\text { of patients }\end{array}$ \\
\hline Granulocytes & l & 2.1 & 3 & 6.4 & I & 2.0 & 0 & 0.0 \\
\hline Haemoglobin & 2 & 4.3 & 0 & 0.0 & 0 & 0.0 & 0 & 0.0 \\
\hline Leukocytes & 5 & 10.6 & 2 & 4.3 & 0 & 0.0 & 0 & 0.0 \\
\hline Thrombocytes & 8 & 17.1 & 3 & 6.4 & 0 & 0.0 & 0 & 0.0 \\
\hline Alopecia & 20 & 42.6 & 0 & 0.0 & 19 & 38.8 & 0 & 0.0 \\
\hline Infection & 8 & 17.0 & 4 & 8.5 & 5 & 10.2 & I & 2.0 \\
\hline Somnolence & 2 & 4.3 & 0 & 0.0 & 3 & 6.1 & 0 & 0.0 \\
\hline Dyspnea & 4 & 8.5 & I & 2.1 & 0 & 0.0 & I & 2.0 \\
\hline Nausea & 4 & 8.5 & 0 & 0.0 & 3 & 6.1 & 0 & 0.0 \\
\hline Vomiting & i & 2.1 & 0 & 0.0 & 0 & 0.0 & 0 & 0.0 \\
\hline Constipation & 3 & 6.4 & 2 & 4.3 & 3 & 6.1 & 0 & 0.0 \\
\hline Pain & 5 & 10.6 & 2 & 4.3 & 7 & 14.3 & 5 & 10.2 \\
\hline Stomatitis & 3 & 6.4 & 0 & 0.0 & 5 & 10.2 & 1 & 2.0 \\
\hline Hyperglycaemia & 2 & 4.3 & 0 & 0.0 & I & 2.0 & 0 & 0.0 \\
\hline Gl-haemorrhage & 1 & 2.1 & 0 & 0.0 & i & 2.0 & 0 & 0.0 \\
\hline Sensorium & 2 & 4.3 & 1 & 2.1 & i & 2.0 & 0 & 0.0 \\
\hline Creatinin-elevated & 2 & 4.3 & 0 & 0.0 & 3 & 6.1 & 0 & 0.0 \\
\hline Pneumonitis & 0 & 0.0 & I & 2.1 & 3 & 6.1 & 0 & 0.0 \\
\hline
\end{tabular}



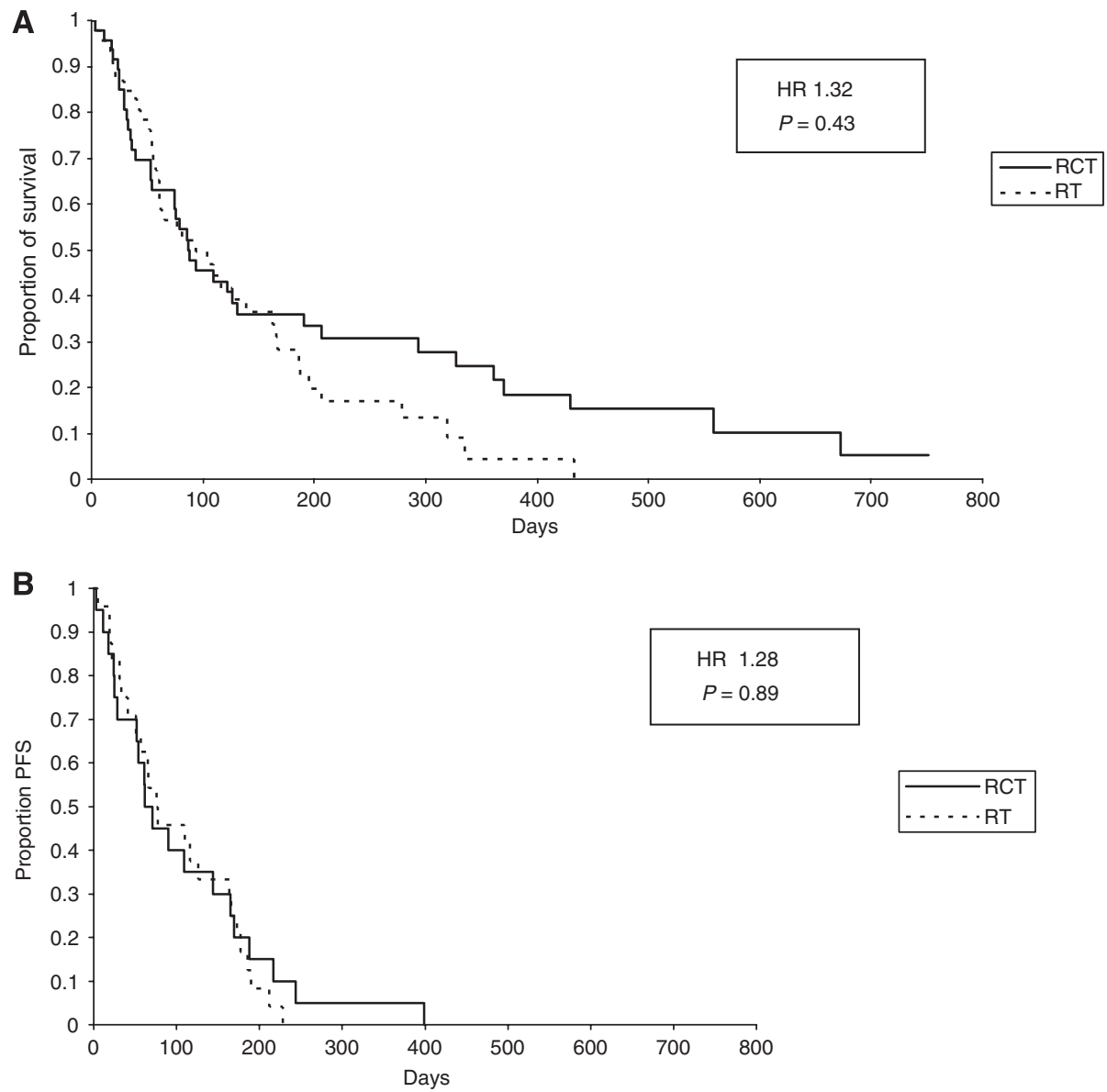

Figure I Overall survival $(\mathbf{A})$ and progression-free survival $(\mathbf{B})$ in both arms ( $\mathrm{HR}=$ Hazard ratio; $\mathrm{RCT}=$ radiochemotherapy; $\mathrm{RT}=$ radiotherapy)

\section{DISCUSSION}

The main goal of the presented study was to elucidate the relevance of concurrent radiochemotherapy with topotecan $\left(0.4 \mathrm{mg} \mathrm{m}^{-2}\right.$ day $^{-1}$ for 5 days over 4 weeks) and WBRT $\left(2 \mathrm{~Gy} \mathrm{day}^{-1}\right.$, $40 \mathrm{~Gy}$ in total) in patients with brain metastases due to lung cancer in comparison with WBRT alone concerning overall survival. We have chosen a schedule of a 2-Gy fraction because we wanted to use the radiosensitising effect of topotecan; thus, both WBRT and chemotherapy should be administered at the same time and over the same period. Second, there are no data concerning higher doses of radiotherapy together with topotecan; the toxicity may increase in an uncalculated manner when 4 or $5 \mathrm{~Gy}$ are used. On the other hand, a treatment course of 4 weeks is a long period for patients with a short life expectancy, as is true in patients with brain metastases. Thus, a shortened schedule would be more attractive for both patients and physicians, and this should be kept in mind when planning such trials.

To test this hypothesis, 320 patients needed to be enrolled. The expected recruitment period lasted 36 months. However, after 34 months, just 96 patients could be included in the study. At this time, an interim analysis was performed that led to the results described above. The low recruitment was mainly caused by patients with a limited number of cerebral metastases and by the resulting opportunity of a local treatment (surgery or stereotactic radiosurgery). As the recruitment rates differed to a greater amount between the different centres, we assume that in addition some centres overestimated the numbers of patients they were able to include. The data presented here once again show the difficulties in estimating the numbers of patients that may be included in each centre, especially in trials with a wide range of exclusion criteria. To avoid such problems, either the number of participating centres should be enlarged or the centres chosen must meet certain requirements.

In the study presented here, the overall response rate in the patients receiving radiochemotherapy was $60 \%$, whereas it was $52 \%$ in the WBRT arm. Compared with our own previous data generated in a phase I/II study, where we found overall response rates of $72 \%$ (Hedde et al, 2007), the outcome of the patients treated with a combined approach was inferior. However, our results confirm the findings of the only two comparable studies testing a topotecan-based radiochemotherapy, in which overall response rates of 46 and 58\%, respectively, were described (Gruschow et al, 2002; Kocher et al, 2005).

With regard to the observed response rates, it was not surprising that neither OAS nor PFS were increased in the combined treatment arm. This was true independent of the kind of lung cancer; thus, even in patients with SCLC, possibly because of the low numbers of patients in each subgroup, we were not able to show improved results when using the combined approach. As lung cancer is not a homogeneous disease, further studies of such a kind should focus on either NSCLC or SCLC to get the definite answer that was missed here. In addition, this approach would have the advantage of being able to choose a chemotherapy optimal for the respective cancer.

Besides the response, another interesting point in brain metastases is the diminished quality of life, which should be observed and analysed in trials dealing with this disease for answering the question whether more aggressive treatment is 
feasible regarding quality of life. However, our study failed to answer this question owing to a very low return of the questionnaires. In further studies, the questions should be asked in a personal meeting or telephone call by a certain member of the team instead of just handing over the questionnaire.

The results presented in this study are in line with data from the very few randomised studies, with a total of only 264 participants comparing radiochemotherapy (by using temozolomide, carboplatin or methyl-CCNU) with radiotherapy alone in patients with brain metastases of solid tumours (Ushio et al, 1991; Antonadou et al, 2002; Guerrieri et al, 2004; Verger et al, 2005), as neither of these found an influence of the overall survival. In two of these studies (Ushio et al, 1991; Antonadou et al, 2002), the objective response rates (96 vs $67 \%$ and 74 vs $36 \%$, respectively) were significantly improved in the patients receiving combined treatment. However, the response rates mentioned there were remarkably high.

Two other studies compared the efficacy of chemotherapy alone with a combination with WBRT (Postmus et al, 2000; Robinet et al, 2001). Postmus et al (2000) used teniposide in 120 patients with
SCLC, and the combined approach resulted in elevated response rates (57 vs 22\%) and a significantly prolonged time-to-progression (6.5 vs 4 months). Robinet et al (2001), by using cisplatin/ vinorelbine with or without WBRT, found response rates of 33 and $27 \%$, respectively. Again, the OAS was not influenced by either study.

In summary, on the basis of the results presented here and the slow recruitment, a continuation of the study did not seem reasonable. The available data of the only phase III trial concerning a combined treatment with topotecan and WBRT in patients with brain metastases due to lung cancer show no advantage for concurrent radiochemotherapy; however, the recruited number of patients is too low to exhibit a small advantage of combined treatment.

\section{ACKNOWLEDGEMENTS}

The study was supported by GlaxoSmithkline.

\section{REFERENCES}

Andrews DW, Scott CB, Sperduto PW, Flanders AE, Gaspar LE, Schell MC, Werner-Wasik M, Demas W, Ryu J, Bahary JP, Souhami L, Rotman M, Mehta MP, Curran Jr WJ (2004) Whole brain radiation therapy with or without stereotactic radiosurgery boost for patients with one to three brain metastases: phase III results of the RTOG 9508 randomised trial. Lancet 363: $1665-1672$

Antonadou D, Paraskevaidis M, Sarris G, Coliarakis N, Economou I, Karageorgis P, Throuvalas N (2002) Phase II randomized trial of temozolomide and concurrent radiotherapy in patients with brain metastases. J Clin Oncol 20: 3644-3650

Ardizzoni A, Hansen H, Dombernowsky P, Gamucci T, Kaplan S, Postmus P, Giaccone G, Schaefer B, Wanders J, Verweij J (1997) Topotecan, a new active drug in the second-line treatment of small-cell lung cancer: a phase II study in patients with refractory and sensitive disease. The European Organization for Research and Treatment of Cancer Early Clinical Studies Group and New Drug Development Office, and the Lung Cancer Cooperative Group. J Clin Oncol 15: 2090-2096

Baker SD, Heideman RL, Crom WR, Kuttesch JF, Gajjar A, Stewart CF (1996) Cerebrospinal fluid pharmacokinetics and penetration of continuous infusion topotecan in children with central nervous system tumors. Cancer Chemother Pharmacol 37: 195-202

Gruschow K, Klautke G, Fietkau R (2002) Phase I/II clinical trial of concurrent radiochemotherapy in combination with topotecan for the treatment of brain metastases. Eur J Cancer 38: 367-374

Guerrieri M, Wong K, Ryan G, Millward M, Quong G, Ball DL (2004) A randomised phase III study of palliative radiation with concomitant carboplatin for brain metastases from non-small cell carcinoma of the lung. Lung Cancer 46: 107-111

Hedde JP, Neuhaus T, Schuller H, Metzler U, Schmidt-Wolf IG, Kleinschmidt R, Losem C, Lange O, Grohe C, Stier S, Ko YD (2007) A phase I/II trial of topotecan and radiation therapy for brain metastases in patients with solid tumors. Int J Radiat Oncol Biol Phys 68: $839-844$

Jawahar A, Matthew RE, Minagar A, Shukla D, Zhang JH, Willis BK, Ampil F, Nanda A (2004) Gamma knife surgery in the management of brain metastases from lung carcinoma: a retrospective analysis of survival, local tumor control, and freedom from new brain metastasis. J Neurosurg 100: $842-847$

Kim JH, Kim SH, Kolozsvary A, Khil MS (1992) Potentiation of radiation response in human carcinoma cells in vitro and murine fibrosarcoma in vivo by topotecan, an inhibitor of DNA topoisomerase I. Int J Radiat Oncol Biol Phys 22: 515-518

Kocher M, Eich HT, Semrau R, Güner SA, Müller RP (2005) Phase I/II trial of simultaneous whole-brain irradiation and dose-escalating topotecan for brain metastases. Strahlenther Onkol 181: 20-25

Korfel A, Oehm C, von Pawel J, Keppler U, Deppermann M, Kaubitsch S, Thiel E (2002) Response to topotecan of symptomatic brain metastases of small-cell lung cancer also after whole-brain irradiation. A multicentre phase II study. Eur J Cancer 38: 1724-1729

Lagerwaard FJ, Levendag PC, Nowak PJ, Eijkenboom WM, Hanssens PE, Schmitz PI (1999) Identification of prognostic factors in patients with brain metastases: a review of 1292 patients. Int J Radiat Oncol Biol Phys 43: $795-803$

Lamond JP, Mehta MP, Boothman DA (1996) The potential of topoisomerase I inhibitors in the treatment of CNS malignancies: report of a synergistic effect between topotecan and radiation. J Neurooncol 30: 1-6 Lassman AB, DeAngelis LM (2003) Brain metastases. Neurol Clin 21: 1-23, vil

Mornex F, Thomas L, Mohr P, Hauschild A, Delaunay MM, Lesimple T, Tilgen W, Bui BN, Guillot B, Ulrich J, Bourdin S, Mousseau M, Cupissol D, Bonneterre ME, De Gislain C, Bensadoun RJ, Clavel M (2003) A prospective randomized multicentre phase III trial of fotemustine plus whole brain irradiation versus fotemustine alone in cerebral metastases of malignant melanoma. Melanoma Res 13: $97-103$

Nieder C, Grosu AL, Astner S, Thamm R, Molls M (2006) Integration of chemotherapy into current treatment strategies for brain metastases from solid tumors. Radiat Oncol 1: 19

O’Brien P, Fleming T (1979) A multiple testing procedure for clinical trials. Biometrics 35: $549-556$

Patchell RA, Tibbs PA, Walsh JW, Dempsey RJ, Maruyama Y, Kryscio RJ, Markesbery WR, Macdonald JS, Young B (1990) A randomized trial of surgery in the treatment of single metastases to the brain. $N$ Engl J Med 322: $494-500$

Pocock SJ (1978) Size of cancer clinical trials and stopping rules. $\mathrm{Br} \mathrm{J}$ Cancer 38: $757-766$

Postmus PE (1995) Brain metastases from small cell lung cancer: chemotherapy, radiotherapy, or both? Semin Radiat Oncol 5: 69-73

Postmus PE, Haaxma-Reiche H, Smit EF, Groen HJ, Karnicka H, Lewinski T, van Meerbeeck J, Clerico M, Gregor A, Curran D, Sahmoud T, Kirkpatrick A, Giaccone G (2000) Treatment of brain metastases of small-cell lung cancer: comparing teniposide and teniposide with wholebrain radiotherapy - a phase III study of the European Organization for the Research and Treatment of Cancer Lung Cancer Cooperative Group. J Clin Oncol 18: $3400-3408$

Riva M, Landonio G, Arena O, Citterio A, Galli C, Ferrante E, Brioschi A, Collice M, Gambacorta M, Scialfa G, Defanti CA, Siena S (2001) Pathophysiology, clinical manifestations and supportive care of metastatic brain cancer. Forum (Genova) 11: 4-26

Robinet G, Thomas P, Breton JL, Léna H, Gouva S, Dabouis G, Bennouna J, Souquet PJ, Balmes P, Thiberville L, Fournel P, Quoix E, Riou R, Rebattu P, Pérol M, Paillotin D, Mornex F (2001) Results of a phase III study of early versus delayed whole brain radiotherapy with concurrent cisplatin and vinorelbine combination in inoperable brain metastasis of nonsmall-cell lung cancer: Groupe Francais de Pneumo-Cancerologie (GFPC) Protocol 95-1. Ann Oncol 12: 59-67 
Saito EY, Viani GA, Ferrigno R, Nakamura RA, Novaes PE, Pellizzon CA, Fogaroli RC, Conte MA, Salvajoli JV (2006) Whole brain radiation therapy in management of brain metastasis: results and prognostic factors. Radiat Oncol 1: 20

Schutte W, Manegold C, von Pawel JV, Lan J, Schäfer B, Kaubitzsch S, Staab HJ (1999) Topotecan - a new treatment option in the therapy of brain metastases of lung cancer. Front Radiat Ther Oncol 33: 354-363

Stewart DJ (2004) Update on the role of topotecan in the treatment of nonsmall cell lung cancer. Oncologist 9(Suppl 6): 43-52

Sundstrom JT, Minn H, Lertola KK, Nordmann E (1998) Prognosis of patients treated for intracranial metastases with whole-brain irradiation. Ann Med 30: 296-299

Sung C, Blaney SM, Cole DE, Balis FM, Dedrick RL (1994) A pharmacokinetic model of topotecan clearance from plasma and cerebrospinal fluid. Cancer Res 54: 5118-5122

Tsao MN, Lloyd N, Wong R, Chow E, Rakovitch E, Laperriere N (2006) Whole brain radiotherapy for the treatment of multiple brain metastases. Cochrane Database Syst Rev 3: CD003869
Ushio Y, Arita N, Hayakawa T, Mogami H, Hasegawa H, Bitoh S, Oku Y, Ikeda H, Kanai N, Kanoh M (1991) Chemotherapy of brain metastases from lung carcinoma: a controlled randomized study. Neurosurgery 28: $201-205$

Verger E, Gil M, Yaya R, Viñolas N, Villà S, Pujol T, Quintó L, Graus F (2005) Temozolomide and concomitant whole brain radiotherapy in patients with brain metastases: a phase II randomized trial. Int J Radiat Oncol Biol Phys 61: 185-191

von Pawel J, Schiller JH, Shepherd FA, Fields SZ, Kleisbauer JP, Chrysson NG, Stewart DJ, Clark PI, Palmer MC, Depierre A, Carmichael J, Krebs JB, Ross G, Lane SR, Gralla R (1999) Topotecan versus cyclophosphamide, doxorubicin, and vincristine for the treatment of recurrent small-cell lung cancer. J Clin Oncol 17: 658-667

Wong ET, Berkenblit A (2004) The role of topotecan in the treatment of brain metastases. Oncologist 9: $68-79$

Zimm S, Wampler GL, Stablein D, Hazra T, Young HF (1981) Intracerebral metastases in solid-tumor patients: natural history and results of treatment. Cancer 48: 384-394 